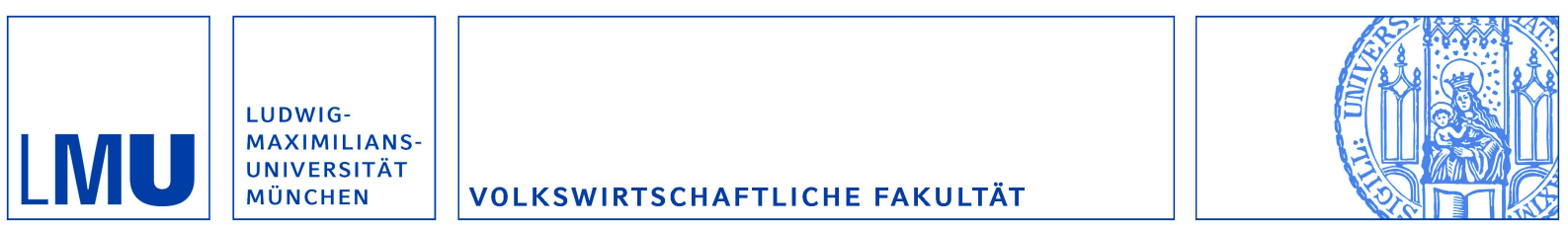

Haufler, Andreas und Nielsen, Søren Bo:

Merger Policy to Promote Global Players? A Simple Model

Munich Discussion Paper No. 2005-13

Department of Economics

University of Munich

Volkswirtschaftliche Fakultät

Ludwig-Maximilians-Universität München

Online at https://doi.org/10.5282/ubm/epub.666 


\title{
Merger Policy to Promote 'Global Players'? A Simple Model*
}

\author{
Andreas Haufler ${ }^{\dagger}$ \\ Søren Bo Nielsen $\ddagger$ \\ University of Munich \\ Copenhagen Business School
}

July 2005

\begin{abstract}
We use a simple framework where firms in two countries serve their respective domestic markets and a world market to analyze under which conditions cost-reducing mergers will be beneficial for the merging firms, the home country, and the world as a whole. For a national merger, the policies enacted by a national merger authority tend to be overly restrictive from a global efficiency perspective. In contrast, all international mergers that benefit the merging firms will be cleared by either a national or a regional regulator, and this laissez-faire approach is also globally efficient. Finally, we derive the properties of the endogenous merger equilibrium.
\end{abstract}

Keywords: merger policy, international trade JEL-Classification: L41, F13, H77

${ }^{*}$ This paper was started when Nielsen was visiting the Center of Economic Studies (CES) in Munich. We thank Joseph Clougherty, Lars Persson, Monika Schnitzer and seminar participants in Regensburg and Dresden for helpful comments. Competent research assistance was provided by Daniel Bauer and Christian Schlichting.

${ }^{\dagger}$ Department of Economics, University of Munich, Akademiestr. 1/II, D-80799 Munich, Germany. Tel. (+49) 89-21803858, e-mail Andreas.Haufler@lrz.uni-muenchen.de

‡Department of Economics, Copenhagen Business School, Solbjerg Plads 3, DK-2000 Frederiksberg, Denmark. Tel. (+45) 38152596, e-mail sbn.eco@cbs.dk 


\section{Introduction}

In political circles the argument is sometimes put forth that mergers of domestic firms have the advantage of creating 'global players', i.e. bigger firms that will be in a better position to compete with foreign firms in world markets. A recent example in Germany has been the merger between the E.ON and Ruhrgas corporations. The German Federal Cartel Office rejected the merger in 2002, and this decision was backed by the scientific Monopoly Commission. Nevertheless, the German Minister of Economics eventually cleared the merger in 2003, overruling the decision by the cartel authority. A main reason for the positive decision of the Ministry of Economics was the 'global player' argument, which was considered to be very important at the onset of energy market liberalization in Europe. ${ }^{1}$

The international competitiveness of domestic firms is an explicit policy objective in the merger guidelines of several countries, including Canada, France, Sweden and the U.K (see Röller, Stennek and Verboven, 2000). According to this policy goal a merger can serve the national interest by increasing the market share of domestic firms in world markets. A second possibility for a merger to improve national welfare, at the expense of foreigners, is that it raises prices for consumers in world markets. Hence, merger policy may be associated with similar goals as strategic export subsidies or tax exporting measures (Brander and Spencer, 1985).

The literature on 'strategic' merger policies has taken two different routes. A first set of papers focuses on nationally optimal merger policies and merger profitability when trade policy instruments are simultaneously available to national governments (Richardson, 1999; Horn and Levinsohn, 2001; Huck and Konrad, 2004; De Stefano and Rysman, 2004). A second line of research is based on the concept of the 'external effects' of a merger introduced by Farrell and Shapiro (1990). This concept has been extended to an open economy setting by Barros and Cabrol (1994) and Head and Ries (1997), who differentiate between the external effects of the merger on other agents in the home country (i.e., consumers and firms not participating in the merger), and the external effects on agents in other countries. This literature has derived rather general

\footnotetext{
${ }^{1}$ The importance of the 'global player' argument in the context of the E.ON-Ruhrgas merger is also stressed by Sinn (2002, pp. 10-12.)
} 
conditions under which a merger benefits, or harms, the parties not participating in the merger. It does not, however, explicitly consider the (possible) cost reductions accompanying a merger, and therefore cannot provide a complete characterization of the post-merger equilibrium.

In this paper we take a different approach by setting up a simple, linear model of Cournot competition in open economies that incorporates the possible cost reductions caused by a merger and is able to make comparisons over discrete merger equilibria. Hence we analyse, in an international setting, the basic trade-off that exists for merger policy when the merger has anti-competitive effects, but also leads to reduced production costs. This trade-off, first analysed by Williamson (1968) for the case of a closed economy, is often referred to as the 'efficiency defense' for a merger. The European Union's new merger control guidelines explicitly acknowledge the possibility of such efficiency gains, and foresee that these enter the Commission's overall assessment of any merger proposal (European Union, 2004, C31/13).

A second difference to the existing literature is that we focus on a three-country model where two competitors in each of two countries serve their respective home markets, and all firms jointly compete in a third (world) market. This market structure captures the situation in many network industries, such as electricity, natural gas, telecommunications or railways. A typical example is the electricity market, where the German duopolists E.ON and $R W E$ compete with other 'national champions' in several European markets, including Sweden, the Netherlands, the Czech Republic, and the United Kingdom. It is also relevant in other markets (for cement, dairy products, etc.) where large national players compete in third markets, but less so in the respective home markets of their competitors.

In this setting we analyze whether a merger is in the interest of the firms involved, the home country, and the world as a whole. The simplicity of our model allows us to explicitly link the producer surplus and welfare effects of a merger to two core parameters, the cost reduction accompanying the merger and the relative size of the home and the foreign market. Moreover, it is straightforward in our three-country framework to carry out parallel analyses of national and international mergers, and to compare the 
different effects. ${ }^{2}$ This comparison reveals that national and international mergers have rather different implications in our setting. For national mergers, a potential conflict of interest arises between the merging firms and a national regulator, and the policies enacted by national merger authorities tend to be overly restrictive from a global efficiency perspective. In contrast, all international mergers that benefit the merging firms will be cleared by either a national or a regional regulator, and this laissez-faire approach is also globally efficient.

In a final step, we analyse whether national mergers, international mergers or no mergers will be the equilibrium market structure, once again relating different regimes to different combinations of cost savings and relative market size. These features link our model to the recent literature on cross-border mergers and on endogenous merger equilibria (Horn and Persson, 2001a,b; Bjorvatn, 2004; Lommerud et al., 2005).

The paper is set up as follows. Section 2 introduces the basic framework of our analysis. Section 3 analyzes the conditions under which national mergers are in the interest of the merging firms. Section 4 turns to optimal merger policy from the perspectives of a single country, and the (model) world as a whole. Section 5 discusses the analogous effects for an international merger. Section 6 analyses the characteristics of the endogenous merger equilibrium. Section 7 concludes.

\section{The model}

In this section we set up a simple model which allows us to analyze some of the dimensions associated with merger policy and the creation of global players. The focus is on an open economy, called the home country $\mathrm{H}$, where the market for a certain good is served by two domestic producers. The same two firms also export to a market abroad, referred to as the world market and indexed W. In the domestic market the two firms do not face any competition, whereas on the market abroad they compete with two firms from another country, called the foreign country, F. These two foreign firms in addition supply the good to their respective domestic market, where again they are the only suppliers. The model framework is illustrated in Figure 1.

\footnotetext{
${ }^{2}$ The strong increase in international mergers since the 1980s is documented in Gugler et al. (2003).
} 
Figure 1: The three-market model

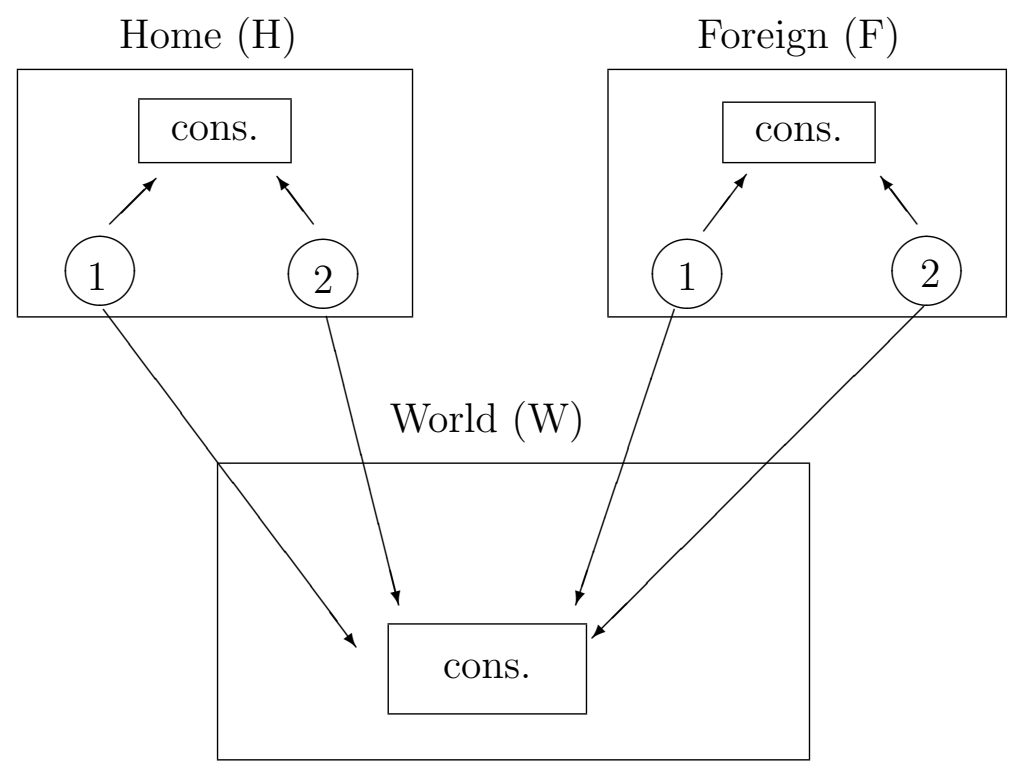

The two domestic firms consider merging, and we shall also study the consequences of merger plans on the part of the two foreign companies. As far as possible we rely on symmetry in setting up the model. Prior to any merger, all firms have the same (constant) level of marginal cost; all markets are characterized by Cournot competition; and the size of the two 'national' markets in $H$ and $F$ are equal. The world market $W$ may be bigger than any of the local markets.

A few remarks on the model are in order. In deciding on the model, our criteria have been that we wish to study merger policy in an open economy; in particular we wish to shed some light on the creation of 'global players', i.e. firms which besides being large in the national market are also important players in the world market. So a merger in the model should have international consequences. At the same time, a merged company should still be facing competition from other firms; these we have placed in the foreign country. For symmetry reasons, also the competitors regard the world market as a market abroad, while at the same time serving their respective own market. ${ }^{3}$

\footnotetext{
${ }^{3}$ As an alternative, we could have set up a two-country model, in which firms in both countries serve each other's market. In that model, a symmetric set-up of the two countries would have been natural. However, that set-up would not correspond well with the image related to creation of global players in a world market. Hence, we opted for the three-market framework above.
} 
In line with much of the literature on merger policy we take imperfect competition to be of the Cournot-Nash type in all markets and the good under consideration to be homogeneous. Moreover, markets are segmented and firms maximize profits in each market separately. ${ }^{4}$

The domestic market is given by the inverted demand schedule ${ }^{5}$

$$
p=a-b\left(x_{1}+x_{2}\right), \quad a>1 .
$$

The price in the domestic market is labeled $p$, and the linear demand schedule is characterized by the intercept $a$ and the slope parameter $b$. The intercept $a$ measures the maximum price consumers are willing to pay for the first unit of the good, while the size of the market is determined primarily by the slope parameter $b$. The two home country firms supply $x_{1}$ and $x_{2}$, respectively, prior to merger, and they do so facing a marginal cost of unity (which is why $a>1$ must hold in our model). There are no fixed costs, and the number of domestic firms (two) is held fixed, except for the possibility of a merger of the two.

Quite conventionally, the maximization of profits in the two duopoly firms results in quantities supplied of $x_{1}=x_{2}=(a-1) /(3 b)$ and a market price of $p=(a+2) / 3$, i.e. $(a-1) / 3$ above the unitary marginal cost.

The domestic firms are fully owned by residents of the home country whereas the foreign firms are owned by residents of the foreign country. In the home country, consumer surplus $c s$ and joint producer surplus of the two firms, $p s$, each amounts to

$$
c s=p s=\frac{2}{b}\left(\frac{a-1}{3}\right)^{2} .
$$

\footnotetext{
${ }^{4}$ Again, several alternatives are available, including Bertrand competition (most meaningfully with differentiated goods) and monopolistic competition. It is well known from the work of Kreps and Scheinkman (1983), however, that modelling a two-stage game with capacity competition and subsequent price competition between firms yields the same results as the simple Cournot model. See also Hay and Werden (1991) for theoretical and empirical arguments in defense of the Cournot model. At the same time, in lieu of segmented markets one could have postulated one big integrated market as in Barros and Cabral (1994) and Head and Ries (1997); yet, that corresponds less well with an image of global players with a base in their domestic market.

${ }^{5}$ The demand schedule can be derived in a general equilibrium framework from a quadratic and quasi-linear utility function.
} 
Hence, the sum of consumer and producer surpluses, total surplus ts, is twice the amount in the above formula,

$$
t s=\frac{4}{b}\left(\frac{a-1}{3}\right)^{2}
$$

In line with the 'efficiency defense' literature on mergers we adopt total surplus as the basic welfare measure in our analysis. ${ }^{6}$

The two home firms both service the market abroad and do so together with the two firms in the foreign country. There, the inverted demand curve is

$$
P=a-B\left(X_{1}+X_{2}+Y_{1}+Y_{2}\right) .
$$

Upper-case letters generally refer to the world market (and lower-case letters to the domestic market). Hence, $X_{1}, X_{2}$ are the supplies of the two home firms, while $Y_{1}, Y_{2}$ denote supplies of the two foreign firms. The slope parameter $B$ will in general be different from the slope parameter $b$ for the market in the home country. A world market which is bigger than the national market is represented by $B<b$.

Maximizing profits, all four firms supply the quantity $X_{1}=X_{2}=Y_{1}=Y_{2}=(a-$ 1) $/(5 B)$, yielding a price of $P=(a+4) / 5$, lying $(a-1) / 5$ above unitary marginal cost.

The two domestic firms together harvest a producer surplus of

$$
P S=\frac{2}{B}\left(\frac{a-1}{5}\right)^{2}
$$

from the world market. World consumers, on the other hand, register a consumer surplus of

$$
C S=\frac{1}{2 B}\left(\frac{4(a-1)}{5}\right)^{2} .
$$

Finally, the domestic market in the foreign country, assumed to be served exclusively by the two foreign firms, is a complete mirror image of the parallel market in the home country, so there is no need to go into details.

\footnotetext{
${ }^{6}$ The alternative view is that merger control authorities base their decisions solely on the maximization of consumer surplus. Clougherty (2005) presents some recent evidence that the merger policy conducted by the United States during the period 1997-2001 was driven primarily by considerations of consumer welfare, rather than total national surplus. He emphasizes, however, that results may be different for other countries, in particular for small open economies.
} 


\section{National mergers: the firm perspective}

In this section we consider the incentives for the two domestic firms to merge and become one firm in the domestic market as well as in the world market. We thus seek to identify the situations in which the sum of producer surpluses on the part of the two firms from both the domestic and world markets stands to increase following a merger. If the two firms merge we postulate, in line with the discussion of several of the motives for mergers in practice, ${ }^{7}$ that the merged firm realizes a reduction of marginal cost of $\Delta \geq 0$, so that it falls to $1-\Delta$. As a special case, there may be no cost reduction at all, $\Delta=0$, but we shall generally allow for a lowering of marginal cost (and conversely ignore any possibility of a cost increase). On many occasions below, the size of the cost reduction will determine whether a merger will be in the interest of the firms involved or other parties affected by the merger.

A merger of the two domestic firms results in a monopoly in the domestic market. In consequence, profit maximization will result in a quantity of $x^{M}=[(a-1)+\Delta] /(2 b)$ and a market price of $p^{M}=[(a+1)-\Delta] / 2$, i.e. $[(a-1)+\Delta] / 2$ above the new marginal cost of $(1-\Delta)$. The superscript 'M' stands for merger of home firms, where needed.

On account of monopoly, consumer surplus in the domestic market has been altered to

$$
c s^{M}=\frac{1}{2 b}\left(\frac{a-1+\Delta}{2}\right)^{2},
$$

while producer surplus is twice this, or

$$
p s^{M}=\frac{1}{b}\left(\frac{a-1+\Delta}{2}\right)^{2} .
$$

Compared with the previous duopoly situation, as long as the cost reduction is nonnegative, the move to monopoly will for sure increase producer surplus.

We next turn to the consequence of the domestic merger for the world market. For later use we distinguish between two cases: In the first, no merger has taken place between the foreign firms; in the second, there already has been a merger between the two foreign firms.

\footnotetext{
${ }^{7}$ Röller et al. (2000, pp. 12-13) distinguish between rationalization, economies of scale, technological progress, purchasing economies, and reduction of slack as the possible sources of efficiency gains following a merger. They observe that savings in variable costs may come in all five forms.
} 


\section{Case 1: No foreign merger}

At the same time as the merged firm becomes a monopoly in the national market, it will be one of three suppliers on the market abroad. Profit maximization implies sales of the monopolist and its foreign competitors to the world market equal to $X^{M}=$ $[a-1+3 \Delta] /(4 B)$, respectively $Y_{1}^{M}=Y_{2}^{M}=[a-1-\Delta] /(4 B)$. The price resulting from these quantities is $P^{M}=[a+3-\Delta] / 4$, resulting in producer surplus on the part of the home merged firm of

$$
P S^{M}=\frac{1}{B}\left(\frac{a-1+3 \Delta}{4}\right)^{2} .
$$

This compares with joint producer surplus of the two foreign firms of

$$
P S_{N}^{M}=\frac{2}{B}\left(\frac{a-1-\Delta}{4}\right)^{2}
$$

where a subscript ' $\mathrm{N}$ ' is here used to distinguish non-merged (foreign) firms.

Comparing (9) with (5) we can find the condition under which the merged firms' profits in the world market rise as a consequence of the merger. This is $\Delta>(a-$ 1) $(\sqrt{1.28}-1) / 3 \approx(a-1) 0.044$. This can be compared with the condition under which the market share of the merged firm $\left(X^{M}\right)$ will exceed the market share of the two foreign firms $\left(Y_{1}^{M}+Y_{2}^{M}\right)$. This latter condition is seen to be $\Delta>(a-1) / 5$ and thus requires a substantially higher cost reduction following the merger. ${ }^{8}$ The reason for this difference is that the consumer price will increase in the world market, following the reduction in the number of firms from four to three.

Adding producer surpluses in the two markets, the sum becomes

$$
p s^{M}+P S^{M}=\frac{1}{b}\left(\frac{a-1+\Delta}{2}\right)^{2}+\frac{1}{B}\left(\frac{a-1+3 \Delta}{4}\right)^{2}
$$

post-merger, compared to pre-merger producer surpluses of

$$
p s+P S=\frac{2}{b}\left(\frac{a-1}{3}\right)^{2}+\frac{2}{B}\left(\frac{a-1}{5}\right)^{2} .
$$

A merger will only be in the two home firms' interest, if the former sum exceeds the latter. The criterion for this can be written

$$
\Gamma \equiv(a-1)^{2}\left[\frac{1}{b}\left(\frac{1}{4}-\frac{2}{9}\right)+\frac{1}{B}\left(\frac{1}{16}-\frac{2}{25}\right)\right]+\Delta(a-1)\left[\frac{1}{2 b}+\frac{3}{8 B}\right]+\Delta^{2}\left[\frac{1}{4 b}+\frac{9}{16 B}\right]>0 .
$$

\footnotetext{
${ }^{8}$ The flip side to this is that the market share of the foreign firms will rise when $\Delta<(a-1) / 5$.
} 
The formula comprises the gains and losses from merging. First, there is a gain from greater monopoly power and concentration in the domestic market (the first part of the first term). Second, at unchanged costs, there is a loss of market share in the world market (the second part of the first term). Third, whatever cost reduction may ensue from the merger obviously benefits the merged firm in both markets (the second and third terms).

Without any drop in marginal cost, only the former two effects matter. It is easily seen that the condition for a merger to be profitable for the merging firms then is $B / b>0.63$. In other words, the world market should not be much larger than the domestic market, if the net gain from the merger absent cost reduction is to be positive. A natural benchmark for the size of the world market, given the presence of four firms there initially against only two in each national market, might be that it is twice as large as any national market in the sense that $B=b / 2$. In our model, this relative size of the world market is not compatible with a net gain from merging in the case where the merger does not result in any lowering of marginal cost.

Underlying these results is the well-known feature that the assumptions of Cournot competition in all markets and a homogeneous good are not very 'friendly' towards merger. Salant, Switzer and Reynolds (1983) have shown that in the absence of any cost reductions, aggregate profits of the merging firms will fall, unless the post-merger market share of these firms is at least $80 \%$ in the case of linear demands. In our model this condition for the merger to be profitable is met in the domestic market, but not in the world market. ${ }^{9}$

Incorporating the possibility of a reduction of marginal cost in the merged firm, the condition on the size of cost reduction for the two home firms to willingly merge is

$$
\Delta>\tilde{\Delta} \equiv(a-1) \frac{4 R+3}{4 R+9}\left[\sqrt{\frac{(63-100 R)(4 R+9) / 225+(4 R+3)^{2}}{(4 R+3)^{2}}}-1\right]
$$

where we have used $R \equiv B / b$ to measure the size of the home market relative to the

\footnotetext{
${ }^{9}$ Results are different under Bertrand competition and heterogeneous goods, where mergers increase profits under rather general conditions (Deneckere and Davidson, 1985). The likelihood for mergers to increase profits is also raised under Cournot competition when product heterogeneity is accounted for (Lommerud and Sørgard, 1997). For a recent summary of arguments why mergers can be profitable for the merging firms, even in a Cournot framework, see Huck, Konrad and Mueller (2005).
} 
world market. The larger is the relative size of the world market, i.e. the lower is $R$, the higher is the minimal cost reduction $\tilde{\Delta}$ required to make the merger profitable. In the complete absence of a world market $(R \rightarrow \infty)$, l' Hôpital's rule gives a $\tilde{\Delta}<0$. In the other limiting case of an arbitrarily large world market $(R \rightarrow 0)$, the critical cost reduction reaches an upper bound. Setting $R=0$ in (12) yields $\tilde{\Delta}=(a-1)(\sqrt{1.28}-$ $1) / 3 \approx(a-1) 0.044$. This is just the condition for the merged firm's profits to increase in the world market. We sum up our findings in

Result 1. (Domestic merger only.) A merger between the two home firms will increase their producer surplus, provided (12) holds. The larger is the world market, relative to the home market, the higher is the cost reduction needed for the merger to be profitable.

\section{Case 2: Foreign firms have merged}

For future use we quickly go through the same steps as above on the assumption that the two foreign competitors have already merged. On account of symmetry in the model we then know that the cost reduction enabled by a merger and thus enjoyed by the foreign companies must fulfill the requirement in (12) above. Given this, will the domestic firms have an incentive to merge, too?

If they merge, the home market moves from duopoly to monopoly, just as above. In the world market, rather than having two home firms and a merged foreign firm, a duopoly between a merged foreign firm and a merged home firm ensues. Maximizing profits, and denoting by 'MM' the situation of double merger, they sell $X^{M M}=Y^{M M}=$ $[a-1+\Delta] /(3 B)$ at a price of $P^{M M}=[a+2-2 \Delta] /(3)$, which is $(a-1+\Delta) / 3$ above the new marginal cost of $1-\Delta$ of both merged firms. From this, the home merged firm realizes a producer surplus of

$$
P S^{M M}=\frac{1}{B}\left(\frac{a-1+\Delta}{3}\right)^{2} .
$$

The two home firms will have an incentive to merge, provided the sum of producer surpluses in (8) and (13) dominates the sum of producer surpluses in (2) and (10). Is this the case for cost reductions greater than $\tilde{\Delta}$ in (12)?

The answer to this question turns out to be affirmative. The argument proceeds in three steps. $(i)$ From the symmetry of our set-up and the fact that the foreign firms 
Table 1: Producer surplus in different merger scenarios

\begin{tabular}{|c||c|c|}
\hline \multicolumn{1}{|c||}{} & \multicolumn{2}{c|}{ Foreign } \\
Home & $\mathrm{N}$ & $\mathrm{M}$ \\
\hline \hline $\mathrm{N}$ & $\frac{2}{b}\left(\frac{a-1}{3}\right)^{2}+\frac{2}{B}\left(\frac{a-1}{5}\right)^{2}$ & $\frac{2}{b}\left(\frac{a-1}{3}\right)^{2}+\frac{2}{B}\left(\frac{a-1-\Delta}{4}\right)^{2}$ \\
& $\frac{2}{b}\left(\frac{a-1}{3}\right)^{2}+\frac{2}{B}\left(\frac{a-1}{5}\right)^{2}$ & $\frac{1}{b}\left(\frac{a-1+\Delta}{2}\right)^{2}+\frac{1}{B}\left(\frac{a-1+3 \Delta}{4}\right)^{2}$ \\
\hline $\mathrm{M}$ & $\frac{1}{b}\left(\frac{a-1+\Delta}{2}\right)^{2}+\frac{1}{B}\left(\frac{a-1+3 \Delta}{4}\right)^{2}$ & $\frac{1}{b}\left(\frac{a-1+\Delta}{2}\right)^{2}+\frac{1}{B}\left(\frac{a-1+\Delta}{3}\right)^{2}$ \\
& $\frac{2}{b}\left(\frac{a-1}{3}\right)^{2}+\frac{2}{B}\left(\frac{a-1-\Delta}{4}\right)^{2}$ & $\frac{1}{b}\left(\frac{a-1+\Delta}{2}\right)^{2}+\frac{1}{B}\left(\frac{a-1+\Delta}{3}\right)^{2}$ \\
\hline
\end{tabular}

have merged, we can infer that the net advantage from this first merger, $\left(p s^{M}+P S^{M}\right)-$ $(p s+P S)$ [see the formulas (8), (9), (2) and (5)] is non-negative. Further, it obviously increases in $\Delta$, and the relevant value of $\Delta$ having led to the first merger must therefore be at least as large as $\tilde{\Delta}$. (ii) The net advantage of the second, home firm merger can be written as $\left(p s^{M}+P S^{M M}\right)-\left(p s+P S_{N}^{M}\right)$ [using formulas (13) and (10)]. This net advantage is also increasing in $\Delta$. (iii) The difference between the two net advantage expressions, equal to $\left(P S^{M M}-P S_{N}^{M}\right)-\left(P S^{M}-P S\right)$, is easily seen to be greater than zero for $\Delta<(a-1) / 5$, which itself is greater than $\tilde{\Delta}$. All in all, if the net advantage from the first merger is positive, so is the net advantage from the second. Thus, if foreign firms have merged, so will the domestic ones.

Result 2. (Domestic merger, given foreign merger.) If foreign companies have already merged, so will the domestic firms.

\section{Conditional merger equilibria}

The relevant producer surpluses for the home firms, respectively the foreign firms, are summed up in Table 1 for the two situations of non-merger (N) and merger (M). In each cell, the upper line gives the producer surplus in the home country while the lower line describes producer surplus in the foreign country.

On the basis of Results 1 and 2 we can now conclude that the game between the group of home firms and the group of foreign firms has two possible merger equilibria, when 
only national mergers are considered. ${ }^{10}$ One equilibrium, the no-merger situation $(\mathrm{N}, \mathrm{N})$, is the outcome for cost reductions $\Delta<\tilde{\Delta}$, while the other, 'twin-merger', equilibrium $(\mathrm{M}, \mathrm{M})$ emerges for $\Delta>\tilde{\Delta}$.

Why is it that the asymmetric situation of $(M, N)$ or $(N, M)$, where one group of firms merges and the other group does not, will not appear as a Nash-equilibrium? The answer is that for a group of firms it is more attractive to move from a three-firm situation in the world market to duopoly there than from a four-firm situation to the three-firm situation. In both cases, the loss of market share (absent any cost reduction) is one sixth, but the increase in market concentration delivers a bigger push to the world market price, when the number of firms there goes from three to two as compared to from four to three.

Result 3. (National merger equilibria.) For cost reductions lower than $\tilde{\Delta}$ in (12), the Nash equilibrium will entail home and foreign firms abstaining from merging. For cost reductions in excess of $\tilde{\Delta}$, the Nash merger equilibrium will imply both groups of firms merging. Asymmetric merger equilibria do not occur in our set-up.

\section{Optimal policy towards national mergers}

\subsection{Nationally optimal merger policy}

In this section we analyse the conditions under which a national merger will raise total surplus in the home country, and will therefore be accepted by national merger control authorities. By adding the producer and consumer surplus measures derived in the previous sections, we can derive total surplus for the home and foreign country, respectively, and for each of the different merger scenarios. ${ }^{11}$ This is given in Table 2. As a preliminary step, we determine the condition for a merger to be in the interest of domestic consumers. From the comparison of (2) and (7) consumers stand to gain

\footnotetext{
${ }^{10}$ This is why we speak here of 'conditional' merger equilibria. The characteristics of the unconditional merger equilibrium will be discussed in Section 6 .

${ }^{11}$ Note that the change in consumer surplus is independent of whether foreign firms have already merged or not, since firms in country $H$ do not serve consumers in $F$ and vice versa.
} 
Table 2: Total surplus in different merger scenarios

\begin{tabular}{|c||c|c|}
\hline \multicolumn{1}{|c||}{ Home } & $\mathrm{N}$ & $\mathrm{M}$ \\
\hline \hline $\mathrm{N}$ & $\frac{4}{b}\left(\frac{a-1}{3}\right)^{2}+\frac{2}{B}\left(\frac{a-1}{5}\right)^{2}$ & $\frac{4}{b}\left(\frac{a-1}{3}\right)^{2}+\frac{2}{B}\left(\frac{a-1-\Delta}{4}\right)^{2}$ \\
& $\frac{4}{b}\left(\frac{a-1}{3}\right)^{2}+\frac{2}{B}\left(\frac{a-1}{5}\right)^{2}$ & $\frac{3}{2 b}\left(\frac{a-1+\Delta}{2}\right)^{2}+\frac{1}{B}\left(\frac{a-1+3 \Delta}{4}\right)^{2}$ \\
\hline $\mathrm{M}$ & $\frac{3}{2 b}\left(\frac{a-1+\Delta}{2}\right)^{2}+\frac{1}{B}\left(\frac{a-1+3 \Delta}{4}\right)^{2}$ & $\frac{3}{2 b}\left(\frac{a-1+\Delta}{2}\right)^{2}+\frac{1}{B}\left(\frac{a-1+\Delta}{3}\right)^{2}$ \\
& $\frac{4}{b}\left(\frac{a-1}{3}\right)^{2}+\frac{2}{B}\left(\frac{a-1-\Delta}{4}\right)^{2}$ & $\frac{3}{2 b}\left(\frac{a-1+\Delta}{2}\right)^{2}+\frac{1}{B}\left(\frac{a-1+\Delta}{3}\right)^{2}$ \\
\hline
\end{tabular}

from the merger if

$$
\Theta \equiv c s^{M}-c s=\frac{1}{2 b}\left[\frac{\Delta^{2}}{4}+\frac{\Delta(a-1)}{2}-\frac{7(a-1)^{2}}{36}\right]>0 \quad \Leftrightarrow \quad \Delta>\Delta^{C}=\frac{(a-1)}{3} .
$$

Hence, consumer surplus will go down, unless it is accompanied by a cost reduction that is substantially higher than the one needed for the merger to increase producer surplus, even if the world market is large (cf. Result 1). In our model this characterizes the 'rather impressive synergies' (Farrell and Shapiro, 1990, 114) that are needed for a merger to reduce consumer prices. ${ }^{12}$

Now let $\Delta^{*}$ be the critical cost reduction beyond which total domestic surplus increases following a merger and recall that $R=B / b$ measures the size of the home market relative to the world market. In the appendix we derive $\Delta^{*}$ as a function of $R=B / b$ :

$$
\Delta^{*}=(a-1) \frac{6 R+3}{6 R+9}\left[\sqrt{\frac{(6 R+9)(250 R+63) / 225+(6 R+3)^{2}}{(6 R+3)^{2}}}-1\right] .
$$

It is immediately seen that the merger must always be accompanied by a cost reduction, if it is to increase total domestic surplus. If the foreign market is infinitely large $(R=0)$, then $(15)$ reduces to $\Delta^{*}=(a-1)(\sqrt{1.28}-1) / 3=\tilde{\Delta}$. In this case the home market does not matter, so the conditions for increasing producer surplus and total national surplus are identical. In the opposite polar case where only the home market matters $(R \rightarrow \infty)$, the critical value $\Delta^{*}$ reaches its maximum of $\left.\Delta^{*}\right|_{R \rightarrow \infty} \approx(a-1) 0.089$.

\footnotetext{
${ }^{12}$ Strictly speaking, if in our simple model $a \geq 4$, a rise in consumer surplus is completely ruled out, as $\Delta$ of course cannot exceed one.
} 
Figure 2: National mergers with national regulation

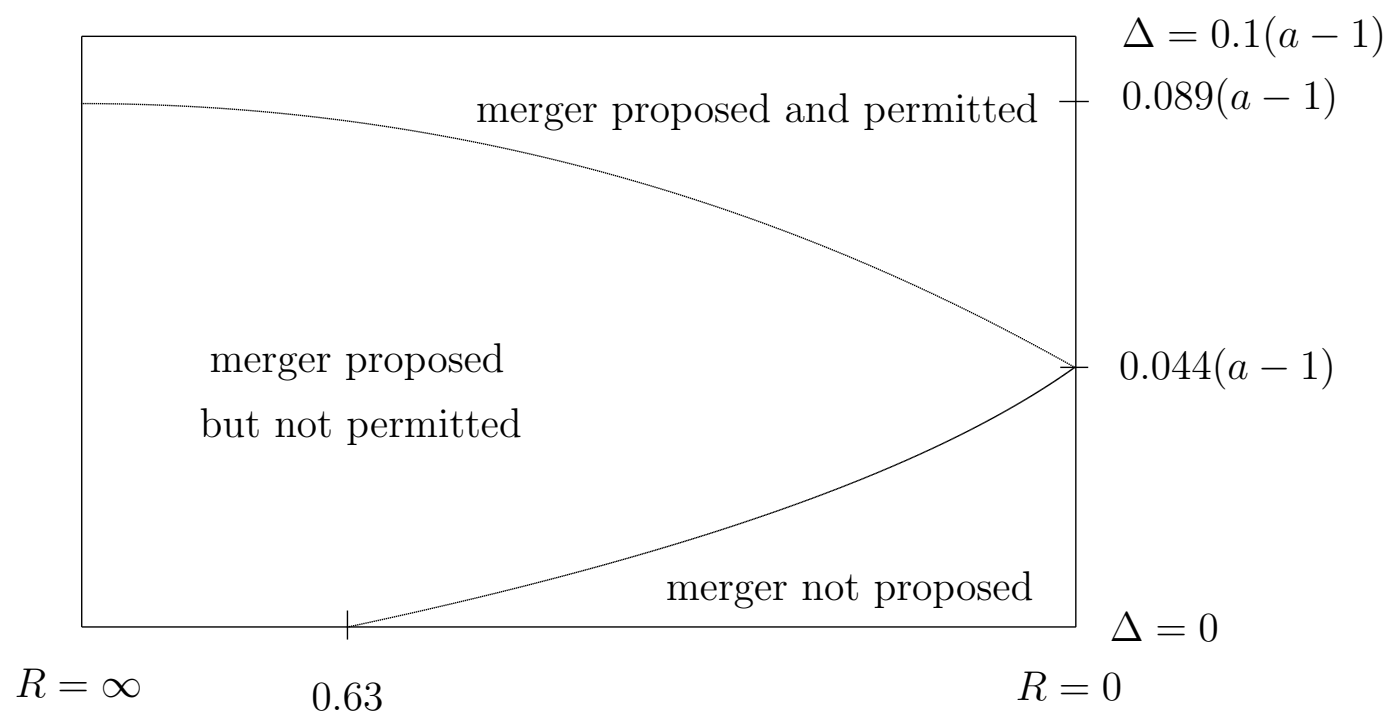

Hence, the larger is the home market relative to the world market, the higher is the critical value of $\Delta$ that is required for an increase in total domestic surplus.

More generally, it is shown in the appendix that the critical cost reduction from a perspective of national surplus maximization, $\Delta^{*}$, exceeds the critical cost reduction from the perspective of the merging firms, $\tilde{\Delta}$ [eq. (12)], for any level of $R$. This result implies that there is a range of cost reductions $\Delta^{*}>\Delta>\tilde{\Delta}$ for which a merger is in the private interest of domestic firms, but not in the interest of the home country as a whole. The reason is the negative 'external effect' (in the language of Farrell and Shapiro, 1990) on domestic consumers. A national merger control authority that is concerned with maximizing total domestic surplus will reject the merger proposal for such values of $\Delta$. When the world market is large ( $R$ is small), the range of $\Delta$ for which the merger is blocked becomes smaller, as most of the burden of higher prices is then borne by consumers in the world market. Figure 2 shows the range of relative size parameters $R$ and cost savings $\Delta$ for which a merger is privately profitable, and is either permitted or rejected by a national regulator. The optimal policy towards a national merger is summarized in

Result 4: (Nationally optimal merger policy.) A national merger authority that maximizes total national surplus will accept a proposed merger, if (15) holds. For the range 
Table 3: Consumer surplus in the world market in different merger scenarios

\begin{tabular}{|c||c|c|}
\hline \multicolumn{1}{|c||}{} & \multicolumn{2}{c|}{ Foreign } \\
Home & $\mathrm{N}$ & $\mathrm{M}$ \\
\hline \hline $\mathrm{N}$ & $\frac{1}{2 B}\left(\frac{4(a-1)}{5}\right)^{2}$ & $\frac{1}{2 B}\left(\frac{3(a-1)+\Delta}{4}\right)^{2}$ \\
\hline $\mathrm{M}$ & $\frac{1}{2 B}\left(\frac{3(a-1)+\Delta}{4}\right)^{2}$ & $\frac{1}{2 B}\left(\frac{2(a-1)+2 \Delta}{3}\right)^{2}$ \\
\hline
\end{tabular}

of cost reductions $\Delta^{*}>\Delta>\tilde{\Delta}$, a merger increases the profits of domestic firms, but reduces total national surplus.

\subsection{Globally optimal merger policy}

When deciding on a merger proposal, national governments in our model neglect two externalities that are caused by the domestic merger: $(i)$ the effect on the producer surplus earned by foreign firms; and (ii) the effect on consumer surplus in the world market. ${ }^{13}$ To complete our analysis of the welfare effects of mergers, Table 3 summarizes the consumer surplus in the world market in each of the different merger scenarios.

We first consider the case where foreign firms have not merged. The change in foreign producer surplus caused by a domestic merger is inferred from Table 1 . The foreign firms benefit from the domestic merger if

$$
\Phi_{1} \equiv \frac{2}{B}\left\{\left(\frac{a-1-\Delta}{4}\right)^{2}-\left(\frac{a-1}{5}\right)^{2}\right\}>0 \quad \Leftrightarrow \quad \Delta<\Delta^{F}=\frac{(a-1)}{5} .
$$

This is just the condition under which the share of foreign firms in the world market will rise (see our discussion in Section 3).

From Table 3, the condition for world consumers to benefit from the home merger is

$$
\Phi_{2} \equiv \frac{1}{2 B}\left\{\left(\frac{3(a-1)+\Delta}{4}\right)^{2}-\left(\frac{4(a-1)}{5}\right)^{2}\right\}>0 \Leftrightarrow \Delta>\Delta^{W}=\frac{(a-1)}{5}
$$

Taken together, eqs. (16) and (17) imply that the (external) externalities caused by a domestic merger are counteracting for any level of $\Delta$, since the turning points for

\footnotetext{
${ }^{13}$ Such externalities on foreigners are termed 'external external effects' by Barros and Cabral (1994).
} 
the signs of the individual effects coincide. If the merger causes only a moderate cost reduction $[\Delta<(a-1) / 5]$, then the domestic merger will benefit foreign producers, but hurt consumers in the world market. If, on the other hand, the cost reduction is large $[\Delta>(a-1) / 5]$, then both of these externalities will change sign, and the merger now hurts foreign producers while benefitting consumers in the world market.

To determine the net externality caused by the domestic merger, we have to add up $\Phi_{1}$ in (16) and $\Phi_{2}$ in (17). It is shown in the appendix that the joint effect of a national merger on foreign producers and world consumers is strictly non-negative in our framework. For $\Delta<(a-1) / 5$, the positive externality that a domestic merger causes for foreign producers exceeds the negative effect on world consumers, whereas for $\Delta>(a-1) / 5$, the positive externality of a domestic merger on world consumers exceeds the negative effect on foreign producer surplus.

Defining $\Delta^{* *}$ as the critical cost reduction needed to increase global welfare, we get

$$
\Delta^{* *}=(a-1) \frac{12 R+5}{12 R+23}\left[\sqrt{\frac{(12 R+23)(500 R+81) / 225+(12 R+5)^{2}}{(12 R+5)^{2}}}-1\right] .
$$

If the world market is negligible $(R \rightarrow \infty)$, this critical value approaches $\Delta^{* *} \approx$ $0.089(a-1)$, the same as the limiting value in the case of national welfare maximization. (In this case, of course, the external externalities are also negligible.) If the world market is very large relative to the home market $(R \rightarrow 0)$, then the critical value is $\Delta^{* *} \approx 0.033(a-1)$, which is less than the corresponding value under the total surplus criterion for national welfare maximization. This reflects that the sum of externalities on agents in $\mathrm{F}$ and $\mathrm{W}$ is strictly positive in this range. More generally, it is shown in the appendix that $\Delta^{* *}<\Delta^{*}$ holds for all finite values of $R$. Hence, there is a range of cost reductions for which the merger increases global welfare, but is nevertheless rejected by a national government that maximizes total domestic surplus. In our model, domestic merger policy will therefore be 'too restrictive' towards national mergers from a perspective of global surplus maximization.

In the case where foreign firms have already merged, completely analogous results obtain. In particular, the effects of a domestic merger on the producer surplus of the foreign (merged) firm and on consumers in the world market have the same signs as in eqs. (16) and (17), and the turning point for the sign of each externality is again $\Delta^{F}=\Delta^{W}=(a-1) / 5$. Our findings are summarized in 
Result 5: (Domestic vs. global welfare maximization.) A domestic merger that raises total national surplus will also raise total surplus worldwide. For moderate cost reductions $(\Delta<(a-1) / 5)$ the gains to foreign producers exceed the losses to world consumers; whereas for large cost reductions $(\Delta>(a-1) / 5)$ the gains to world consumers exceed the losses to foreign producers.

\section{International mergers}

A different scenario that can readily be addressed in our framework is a cross-country merger, say between H's firm 1 and F's firm 1. In each of the markets $H$ and F, the merged firm is still part of a duopoly, but it may now have gained a cost advantage over its domestic competitor. In the world market W, the merged firm acts as one competitor, thus reducing the total number of firms in this market to three. In this section we analyze the optimal policies towards such international mergers, and compare them to the results derived above for the case of national mergers.

In the home market (and equivalently in market $\mathrm{F}$ ), profit maximization by the merged firm 1 (with unit cost of $1-\Delta^{I}$ ) and its competitor (with unit costs of 1 ) yields Cournot duopoly outputs of $x_{1}^{I}=\left[a-1+2 \Delta^{I}\right] /(3 b)$, respectively $x_{2}^{I}=\left[a-1-\Delta^{I}\right] /(3 b)$, where the superscript 'I' stands for an international merger. The resulting market price is $p^{I}=\left(a+2-\Delta^{I}\right) / 3$, showing that the cost savings by the merged firm are partly passed on to consumers. Consumer surplus is

$$
c s^{I}=\frac{1}{2 b}\left(\frac{2(a-1)+\Delta^{I}}{3}\right)^{2} .
$$

Comparing (19) to (2) shows immediately that an international merger can never hurt consumers in either country $\mathrm{H}$ or $\mathrm{F}$, even if $\Delta^{I}=0$.

The producer surplus of the merged firm and the non-merged firm (subscript ' $\mathrm{N}$ ') in the home country are

$$
p s^{I}=\frac{1}{b}\left(\frac{a-1+2 \Delta^{I}}{3}\right)^{2}, \quad p s_{N}^{I}=\frac{1}{b}\left(\frac{a-1-\Delta^{I}}{3}\right)^{2} .
$$

In comparison to a national merger, which causes a domestic monopoly [cf. (8)], the producer surplus of the merged firm (in both countries together) is now increased by 
less. In the world market, the effects of an international merger are the same as those caused by a national merger, and the surplus of the merged firm and its competitors in eqs. (9)-(10) is unchanged from our treatment in Section 3. Hence $P S^{M}=P S^{I}$ and $P S_{N}^{M}=P S_{N}^{I}$. Note, finally, that the surpluses of both the merged firm and the non-merged firms are now divided equally between countries $\mathrm{H}$ and $\mathrm{F}$.

\subsection{Privately profitable international merger}

The condition for the merger to be privately profitable is derived in the Appendix and given by

$$
\Delta^{I}>\tilde{\Delta}^{I} \equiv(a-1) \frac{64 R+27}{(128 R+81)}\left[\sqrt{\frac{(64 R+27)^{2}+2.52(128 R+81)}{(64 R+27)^{2}}}-1\right] .
$$

As in the case of national mergers [eq. (12)], equation (21) determines the critical cost reduction $\tilde{\Delta}^{I}$ for varying levels of the relative market size parameter $R$. It is seen that, in contrast to a national merger, an international merger can never be profitable in the absence of cost savings (i.e., for $\Delta^{I}=0$ ). This is because the merged firm will have no gains in markets $\mathrm{H}$ and $\mathrm{F}$ in this case, relative to the pre-merger situation, while its joint market share in country $\mathrm{W}$ falls. If the world market is of negligible size $(R \rightarrow \infty)$, l' Hôpital's rule gives $\tilde{\Delta}^{I}=0$. Not surprisingly, in the other extreme case where only the world market matters $(R \rightarrow 0)$, the critical cost reduction is the same as the limit value for a national merger, $\tilde{\Delta}^{I}=(a-1)(\sqrt{1.28}-1) / 3 \approx(a-1) 0.044$. Moreover, it is shown in the appendix that, for any positive level of $R$, condition (21) is stricter than the corresponding condition for a national merger [eq. (12)].

Note that if a merger between a first pair of firms in countries $\mathrm{H}$ and $\mathrm{F}$ is profitable, then the same is also true for a merger between the second pair of firms. The reasoning is analogous to the one in the case of national mergers (Results 2 and 3 ). The difference between the first and the second merger lies only in their effect on the world market, and the change from three to two suppliers will lead to a larger price increase in this market than the move from four to three suppliers. Hence, if the first international merger takes place, so will the second. ${ }^{14}$

\footnotetext{
${ }^{14}$ In parallel with the analysis in Section 4, we here investigate 'conditional' international-merger equilibria. Unconditional (endogenous) merger equilibria are the subject of Section 6.
} 
Result 6. (International merger.) A merger between one home firm and one foreign firm increases the joint producer surplus if (21) holds. The required cost reduction is always higher or equal than in the case of a national merger. If (21) holds, the conditional merger equilibrium will feature two internationally merged firms.

\subsection{Regional policies towards cross-country mergers}

We now consider optimal policy towards international mergers. For the cross-country merger considered here, it is natural to assume that merger control is in the hands of a regional merger authority. This is in line, for example, with the division of competences for merger control in the European Union. We assume that this regional regulator maximizes the total joint surplus in countries $\mathrm{H}$ and F. However, due to the complete symmetry of the model in the case of cross-country mergers, it is sufficient to evaluate the total surplus in the home country. In addition to the surplus of the merged firm, this measure includes the consumer surplus in the home market in (19) and the profits of the non-merged home firm in (20). We have already established that consumers in countries $\mathrm{H}$ and $\mathrm{F}$ will benefit from any international merger that is accompanied by a positive cost reduction. The cost reduction needed to raise the home country's total surplus is (see the appendix)

$$
\Delta^{I *}=(a-1) \frac{64 R+9}{176 R+99}\left[\sqrt{\frac{(64 R+9)^{2}-3.96(176 R+99)}{(64 R+9)^{2}}}-1\right] .
$$

This expression equals zero, if the world market is of negligible size $(R \rightarrow \infty)$, and it is negative when the world market is very large $(R \rightarrow 0)$. This shows that the national government will accept any international merger that is proposed. The core difference to the case of a national merger (Result 4) is that the merged firm will still face a domestic competitor in the home market. In the absence of a world market, both producers and consumers in the home country will just be indifferent towards a merger that entails no cost reductions. ${ }^{15}$ Adding the world market to the picture, the home

\footnotetext{
${ }^{15}$ This corresponds to the benchmark result in Cournot models that the aggregate external effect of a merger cannot be negative, if the merging firms have a market share of at most 50\% (Levin, 1990). For the international merger considered here, this market share is just $50 \%$ when $\Delta^{I}=0$.
} 
Figure 3: International mergers with national or regional regulation

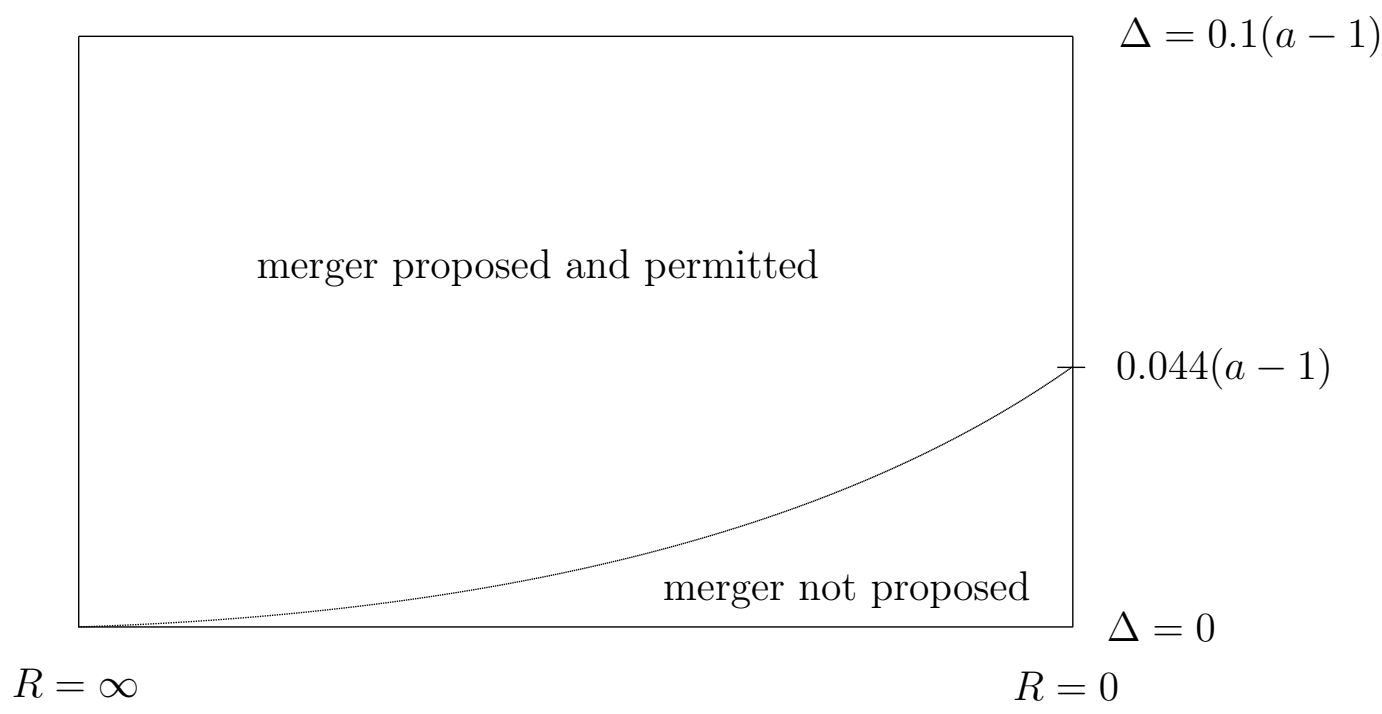

country always gains from the merger, even in the absence of cost savings, because the merger increases concentration and consumer prices in market W.

On account of symmetry, the effects of the international merger on the total surplus in countries $\mathrm{H}$ and $\mathrm{F}$ taken together will just be twice the isolated effect on country $\mathrm{H}$. Therefore, the critical value derived in (22) is unchanged if joint surplus maximization in the producing countries $\mathrm{H}$ and $\mathrm{F}$ is the policy objective. Figure 3 shows the parameter combinations for which international mergers are proposed and cleared by the regional merger authority. We summarize in

Result 7: (Optimal policy towards international merger.) An international merger will never be blocked by a regulator that maximizes total joint surplus in $H$ and $F$.

\subsection{Global welfare}

It remains to determine whether it is possible for an international merger to raise the profits of the merging firms and total surplus in countries $\mathrm{H}$ and $\mathrm{F}$, but nevertheless reduce total surplus worldwide. This is not a trivial issue, given that we know from our previous analysis that consumers in country $\mathrm{W}$ will be hurt by a merger that is accompanied by only moderate cost reductions. The critical cost reduction required for 
the international merger to increase global welfare is (see the appendix)

$$
\Delta^{I}>\Delta^{I * *} \equiv(a-1) \frac{128 R+45}{(352 R+207)}\left[\sqrt{\frac{(128 R+45)^{2}+3.24(352 R+207)}{(128 R+45)^{2}}}-1\right] \text {. }
$$

Evaluating this expression for $R=0$ shows that $\left.\Delta^{I * *}\right|_{R=0} \approx 0.033(a-1)$. If the world market is very large, the cost reduction that makes the merger profitable for the involved firms will also ensure that the merger increases total surplus worldwide. In the other extreme case where only the home market matters, $\left.\Delta^{* *}\right|_{R \rightarrow \infty}=0$, which is the same threshold as for total national surplus to increase. More generally, it is shown in the appendix that in our set-up $\Delta^{I * *} \leq \tilde{\Delta}^{I}$ holds for any level of $R$. Hence we have

Result 8: (Global welfare effects of international merger.) Any international merger that raises the producer surplus of the merged firms will also increase global surplus.

From a perspective of global surplus maximization, there is thus no need for either national or regional control of international mergers in our model. The reason is that an international merger does not create a monopoly in either the home or the foreign market, and hence will be profitable for the merging firms only if cost reductions are sufficiently high. This threshold is in turn sufficient to ensure that global world surplus increases. Note, however, that some of the gains to the producing countries $\mathrm{H}$ and $\mathrm{F}$ come at the expense of consumers in country $\mathrm{W}$, whose surplus is still reduced by the international merger as long as $\Delta^{I}<\Delta^{W}=(a-1) / 5$.

\section{Endogenous merger equilibria}

A recent development in the merger literature is that the firms' choice between different possible partners is endogenised. Horn and Persson (2001a, 2001b) treat mergers as a cooperative game of coalition formation and show that an equilibrium market structure maximizes the sum of industry profits, rather than just the profits of the merging firms. This result is very intuitive: if total industry profits are not maximized under a given ownership structure, then there will always be an incentive for at least one firm (including those which have not merged) to make a merger offer to some other firm 
that leaves both of these firms better off. ${ }^{16}$

It is straightforward to apply this general approach to our simple model. As we have argued above for both national and international mergers, any conditional merger equilibrium will feature either no mergers at all, or two merged firms (Results 3 and 6). Hence all that remains to be analyzed is under which conditions the equilibrium ownership structure is characterized by two national firms, two international firms, or no mergers at all. ${ }^{17}$

If the cost savings associated with a national and an international merger is the same $\left(\Delta=\Delta^{I}\right.$ ), then we already know (from Result 6) that firms will always prefer the national mergers, as this will give them monopoly power in their respective home markets. However, as we have discussed in Section 4, these mergers may not be permitted by national merger authorities. In such cases only international mergers are feasible and this will also be the merger equilibrium, provided that cross-border mergers are privately profitable.

Figure 4 summarizes the equilibrium merger structure for different parameter combinations when national mergers are regulated by national merger authorities and crosscountry mergers are regulated by a regional merger authority. Higher cost savings are associated with more national mergers in equilibrium, because firms always prefer national over international mergers, and (national) merger authorities will accept more national mergers in this case. Similarly, a large relative size of the world market $(R \rightarrow 0)$ implies that most of the losses in consumer surplus occur in third countries, which again

\footnotetext{
${ }^{16}$ In general, only the sum of profits among the decisive owners matters for the equilibrium merger structure (Horn and Persson, 2001b). In our model, however, the owners of all firms are decisive.

${ }^{17}$ In line with the relevant literature, we exclude the case of a worldwide monopoly. The latter would obviously be in the interest of all firms, but it would also go against consumer interests in all countries. Having excluded worldwide monopoly, there is in principle one more merger outcome to consider. This is the 'double-merger' situation, where, say, the two country $\mathrm{H}$ firms and one of the $\mathrm{F}$ firms merge. This outcome creates a monopoly in $\mathrm{H}$, but only duopoly in $\mathrm{F}$ and $\mathrm{W}$. We shall ignore this outcome in the following, for two reasons: First, the four firms together will typically prefer the outcome with two national mergers, as this allows deeper exploitation of cost reduction and monopoly power. Second, merger authorities in country $\mathrm{H}$ are likely to be rather unsympathetic to the twinmerger, as it implicitly leads to a loss of market share in W for H's shareholders (they get to own 2/3 of the merged firm which has only around half of the world market).
} 
Figure 4: Equilibrium merger structure with national regulation

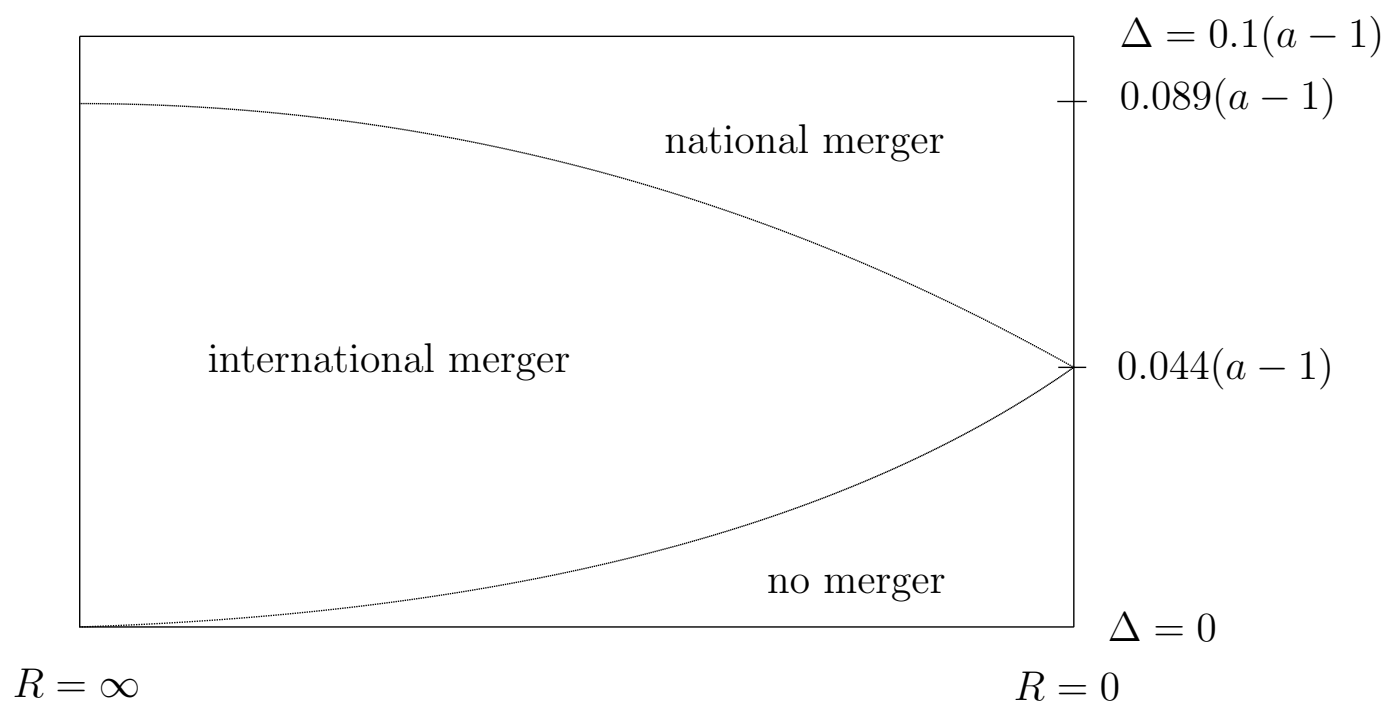

will induce national merger authorities to accept a larger share of national mergers. In contrast, if the share of sales in world markets is low $(R \rightarrow \infty)$, and cost savings are moderate, then the equilibrium market structure is characterized by cross-border mergers. Finally, if the world market is relatively large and cost savings are close to zero, then no mergers will occur in equilibrium.

The assumption that cost savings are identical for a national and a regional merger is, however, a restrictive one. Reasons why international mergers may be associated with higher cost savings include reduced aggregate transport costs (Horn and Persson, 2001a; Bjorvatn, 2004), higher synergies due to a more diverse knowledge base, or a weakening of national trade unions as a result of international mergers (Lommerud, Straume and Sørgard, 2005).

In our model, comparing total industry profits for national and international mergers in the case where $\Delta<\Delta^{I}$ involves only to compute total producer surplus in the home market. The surplus in the foreign market will be symmetric, whereas the surplus in the world market is the same under the two different types of duopoly. Subtracting the producer surplus of the merged firm in the case of a national merger [eq. (8)] from the sum of the two surplus measures for an international merger [eq. (20)] gives

$$
p s^{I}+p s_{N}^{I}-p s^{M}=\frac{1}{b}\left\{\frac{5}{9}\left(\Delta^{I}\right)^{2}+\frac{2}{9} \Delta^{I}(a-1)-\frac{(a-1)^{2}}{36}-\frac{\Delta(a-1)}{2}-\frac{\Delta^{2}}{4}\right\} .
$$


The critical value of $\Delta^{I}$ for which the international merger causes higher total industry profits, is then

$$
\Delta^{I}>\hat{\Delta}^{I}=\frac{-2(a-1)+\sqrt{4(a-1)^{2}+5\left\{(a-1)^{2}+9 \Delta[\Delta+2(a-1)]\right\}}}{10} .
$$

Clearly, the minimum required cost savings that make the international mergers more profitable $\left(\hat{\Delta}^{I}\right)$ are a rising function of the cost savings arising from a national merger. In the special case where the latter does not cause any cost reduction $(\Delta=0)$, international mergers will be more profitable for the industry as a whole, if they lead to cost savings of at least $\hat{\Delta}^{I}=(a-1) / 10$. If this condition is fulfilled, then the endogenous equilibrium ownership structure will always be one with two internationally merged firms. This is summarized in our last result:

Result 9: (Endogenous merger equilibrium.) If domestic and international mergers lead to identical cost savings, then the equilibrium market structure is characterized by international mergers, if cost savings are moderate and the share of sales in third markets is low. The equilibrium market structure will also be characterized by international mergers, whenever condition (24) holds.

\section{Conclusions}

In this paper we have set up a simple three-country model with segmented markets and Cournot competition between firms. A home country and a foreign country both have two domestic firms which supply the respective domestic markets plus a third (world) market. Within this set-up we have formally analyzed the effects of national and crossborder mergers on the firms involved, on selected groups of consumers, and on the world as a whole. We argued that when national merger authorities pursue national surplus, they tend to be overly restrictive vis-a-vis national mergers, so some proposed national mergers will be rejected by authorities despite being beneficial from a world perspective. In contrast, proposed international mergers will be efficiently cleared by national and regional authorities. Finally, we considered endogenous merger formation and demonstrated how the possible outcomes - no merger, twin-national merger, or 
twin-international merger - depend on both the extent of cost reduction accompanying a merger and the size of the world market relative to the national markets.

Despite its simplicity, our model allows to derive a foundation for the empirical observation that mergers seem to come in waves. In particular, we found that whenever any two of the four firms in our model decides to merge, either within a country or cross-border, so will the remaining two firms. Further, a striking result of our analysis is the pronounced difference between national and international mergers. This result captures, in a stylized form, an important asymmetry between national and cross-border mergers in markets where national players dominate. In these markets a national merger will indeed reduce the number of firms that actively supply the market, whereas an international merger will not. Our model shows that the conditions for an international merger to be in the interest of the participating firms are unambiguously stricter than in the case of a national merger, but when indeed proposed, international mergers will not be vetoed by neither national nor regional merger authorities. This finding is compatible with the permissive stance of merger control at the level of the European Union: of almost 1600 merger proposals that the European Commission had to decide upon until the end of 2000 , more than 85 per cent were accepted immediately and only 13 mergers, or less than 1 per cent, were finally rejected (Schmidt, 2001, p. 237).

Lastly, our analysis does not lend support to the hypothesis that national or regional merger policy is used as a beggar-thy-neighbour instrument. This is partly due to the property of the Cournot oligopoly model that a merger will typically benefit the firms that are not participating in it. There is another element in our model which is responsible for this result, however. It is well known that the strategic effects of national policies are strongest when all domestic output is sold in a third market. This setting underlies, for example, the result of De Stefano and Rysman (2004) that countries will always favour a single national champion, as this policy allows them to use strategic trade policies most effectively. In contrast, in our model the output of the merged firm is also consumed in the country that undertakes the regulation. This ensures that mergers are not accepted unless they are associated with cost savings, which outweigh the efficiency losses resulting from reduced competition at home. 


\section{Appendix}

\section{A. National merger}

Nationally optimal merger policy: We add (14) and (11) in the case where the foreign firms have not merged. This implicitly defines $\Delta^{*}$ by

$$
\Lambda \equiv \frac{3}{2 b}\left(\frac{a-1+\Delta}{2}\right)^{2}+\frac{1}{B}\left(\frac{a-1+3 \Delta}{4}\right)^{2}-\frac{4}{b}\left(\frac{a-1}{3}\right)^{2}-\frac{2}{B}\left(\frac{a-1}{5}\right)^{2}=0 .
$$

Multiplying by $B$, introducing $R=B / b$ and solving for $\Delta^{*}$ yields (15).

To see that $\Delta^{*}>\tilde{\Delta}$ for any level of $R$, note first from (A.1) that $\Lambda(\Delta) \equiv \Gamma(\Delta)+\Theta(\Delta)$ is monotonically increasing in $\Delta$. Moreover, $\Lambda(\tilde{\Delta})<0$ since $\Gamma(\tilde{\Delta})=0$ [eq. (11)] and $\Theta(\tilde{\Delta})<0$ [eq. (14)]. Hence we can unambiguously infer that $\Delta^{*}$, which solves (A.1), must exceed $\tilde{\Delta}$.

Globally optimal merger policy: To determine the net externality caused by the domestic merger, we have to add up $\Phi_{1}$ in (16) and $\Phi_{2}$ in (17). This yields

$$
\Phi \equiv \frac{1}{160 B}\left[25 \Delta^{2}-10 \Delta(a-1)+(a-1)^{2}\right] \geq 0
$$

which is positive for all values of $\Delta \neq(a-1) / 5$ and zero for $\Delta=(a-1) / 5$.

Adding up $\Lambda$ in (A.1) and $\Phi$ in (A.2) gives a measure of the change in global total surplus $^{18}$ defined by

$$
\Omega \equiv \Delta^{2}\left[\frac{3}{8 b}+\frac{23}{32 B}\right]+\Delta(a-1)\left[\frac{3}{4 b}+\frac{5}{16 B}\right]-(a-1)^{2}\left[\frac{5}{72 b}+\frac{9}{800 B}\right],
$$

which is negative at $\Delta=0$ and monotonically rising in $\Delta$. The condition $\Omega=0$ implicitly determines the critical level of cost reductions, $\Delta^{* *}$ given in (18), which is positive for any level of $R$. Since $\Lambda\left(\Delta^{*}\right)=0$ and $\Phi\left(\Delta^{*}\right) \geq 0$, it follows that $\Omega\left(\Delta^{*}\right) \geq 0$, with the inequality holding strictly when $\Delta^{*} \neq(a-1) / 5$. From the positive monotonicity of $\Omega(\Delta)$ it then follows that $\Delta^{* *} \leq \Delta^{*}$.

\footnotetext{
${ }^{18}$ Foreign consumer surplus is not included in this welfare measure, because it is unaffected by the domestic merger.
} 


\section{B. International merger}

Profitability for merging firms: The change in producer surplus for the merging firms is $p s^{I}+P S^{I}-p s-P S>0$. Using eqs. (2), (5), (9) and (20), this gives

$$
\Gamma^{I} \equiv(a-1)^{2}\left[\frac{1}{B}\left(\frac{1}{32}-\frac{1}{25}\right)\right]+\Delta^{I}(a-1)\left[\frac{4}{9 b}+\frac{3}{16 B}\right]+\left(\Delta^{I}\right)^{2}\left[\frac{4}{9 b}+\frac{9}{32 B}\right] .
$$

Setting (A.4) equal to zero, multiplying by $B$, introducing $R=B / b$ and solving for $\Delta^{I}$ gives (21).

To show that the critical cost reduction needed to benefit the merging firms [eq. (21)] is always stricter (or equally strict) than the parallel condition for a national merger [eq. (12)], we evaluate the net gain to the firms from an international merger, $\Gamma^{I}$ in (A.4), at the critical level of cost reduction for the national merger $\left(\tilde{\Delta}^{I}\right)$ and show that $\Gamma^{I}\left(\tilde{\Delta^{I}}\right) \leq 0$. Substituting (12) into (A.4) and rearranging gives

$$
\begin{aligned}
& \Gamma^{I}\left(\tilde{\Delta^{I}}\right)=\frac{1}{R b}\left[\frac{-7(a-1)^{2}}{800}+\frac{(a-1)^{2}(4 R+3) \rho}{288(4 R+9)^{2}}\right], \\
\rho & \equiv\left(512 R^{2}+48 R\right)\left(1-\sqrt{1+\frac{(63-100 R)(4 R+9)}{225(4 R+3)^{2}}}\right) \\
+ & \frac{\left(512 R^{2}+708 R+243\right)(63-100 R)(4 R+9)}{225(4 R+3)^{2}}
\end{aligned}
$$

For $R=0$ it is easily confirmed that $\Gamma^{I}\left(\tilde{\Delta}^{I}\right)=0$. Moreover, straightforward, but tedious calculations show that $d \Gamma^{I}\left(\tilde{\Delta^{I}}\right) / d R<0$, establishing the result. ${ }^{19}$

Regionally optimal merger policy: The sum of all changes in domestic surplus is, from (19) and (20)

$$
\Lambda^{I}=\left(\Delta^{I}\right)^{2}\left[\frac{11}{18 b}+\frac{11}{32 B}\right]+\Delta^{I}(a-1)\left[\frac{4}{9 b}+\frac{1}{16 B}\right]+\frac{11(a-1)^{2}}{800 B} .
$$

Setting this equal to zero, introducing $R=B / b$ and solving for $\Delta^{I}$ gives (22).

Globally optimal merger policy: The sum of all welfare changes caused by the international merger is $(i)$ the change in total surpluses in $\mathrm{H}$ and $\mathrm{F}$ which, due to

\footnotetext{
${ }^{19}$ We have performed these calculations using Mathematica. The results are available from the authors upon request.
} 
symmetry are two times the change given in (A.5); and (ii) the change in consumer surplus for consumers in $\mathrm{W}$, as given in (17). Thus

$$
\Omega^{I}=\left(\Delta^{I}\right)^{2}\left[\frac{11}{9 b}+\frac{23}{32 B}\right]+\Delta^{I}(a-1)\left[\frac{8}{9 b}+\frac{5}{16 B}\right]-\frac{9(a-1)^{2}}{800 B} .
$$

This sum is negative at $\Delta^{I}=0$ and monotonically rising in $\Delta^{I}$. Introducing $R$ and setting $\Omega^{I}=0$ gives (23).

To prove that any international merger that raises the profits of the merged firm will also raise world welfare, we have to show that $\Omega^{I}$ in (A.6) is positive when evaluated at $\tilde{\Delta}^{I}$. Substituting $\tilde{\Delta}^{I}$ from (21) into (A.6) and rearranging gives

$$
\begin{array}{r}
\Omega^{I}\left(\tilde{\Delta}^{I}\right)=\frac{(a-1)^{2}}{R b}\left[\frac{(352 R+207)}{288} \frac{(64 R+27)^{2}}{(128 R+81)^{2}}\left(\alpha^{2}-2 \alpha+1\right)\right. \\
\left.+\frac{(128 R+45)}{144} \frac{(64 R+27)}{(128 R+81)}(\alpha-1)-\frac{9}{800}\right] \\
\text { where } \quad \alpha \equiv \sqrt{\frac{(128 R+54)^{2}+10.08(128 R+81)}{(128 R+54)^{2}}} .
\end{array}
$$

Evaluating this with Mathematica shows that $\Omega^{I}\left(\tilde{\Delta}^{I}\right)>0$ holds for all finite levels of $R$, with $\Omega^{I}\left(\tilde{\Delta}^{I}\right) \rightarrow 0$ for $R \rightarrow \infty$. 


\section{References}

Barros, P.P. and L. Cabral (1994), Merger policy in open economies, European Economic Review 38, 1041-1055.

Bjorvatn, K. (2004), Economic integration and the profitability of cross-border mergers and acquisitions, European Economic Review 48, 1211-1226.

Brander, J.A. and B. Spencer (1985), Export subsidies and international market share rivalry, Journal of International Economics 18, 83-100.

Clougherty, J.A. (2005), Industry Trade-Balance and Domestic Merger Policy: Empirical evidence from U.S. merger policy for manufacturing sectors, Contemporary Economic Policy 23, 404-415.

De Stefano, M. and M. Rysman (2004), Competition policy as strategic trade with differentiated products, mimeo, Boston University.

Deneckere, R. and C. Davidson (1985), Incentives to form coalitions with Bertrand competition, Rand Journal of Economics 16 , 473-486.

European Union (2004), Guidelines on the assessment of horizontal mergers under the Council Regulation on the control of concentration betweenb undertakings. Official Journal of the European Union 2004/C31/03 (5 February 2004), Brussels.

Farrell, J. and C. Shapiro (1990), Horizontal mergers: An equilibrium analysis, American Economic Review 80, 107-126.

Gugler, K., D.C. Mueller, B. Yurtoglu and Ch. Zulehner (2003), The effects of mergers: An international comparison, International Journal of Industrial Organization 21, 625-653.

Hay, G.A. and G.J. Werden (1993), Horizontal mergers: Law, policy and economics, American Economic Review 83, 173-177.

Head, K. and J. Ries (1997), International mergers and welfare under decentralized competition policy, Canadian Journal of Economics 30, 1104-1123. 
Horn, H. and J. Levinsohn (2001), Merger policies and trade liberalization, Economic Journal 111, 244-276.

Horn, H. and L. Persson (2001a), The equilibrium ownership of an international oligopoly, Journal of International Economics 53, 307-333.

Horn, H. and L. Persson (2001b), Endogenous mergers in concentrated markets, International Journal of Industrial Organization 19, 1213-1244.

Huck, S. and K.A. Konrad (2004), Merger profitability and trade policy, Scandinavian Journal of Economics 106, 107-122.

Huck, S., K.A. Konrad and W. Mueller (2005), Merger without cost advantages, CESifo Working Paper No. 1461. Munich.

Kreps, D. and J.A. Scheinkman (1983), Quantity precommitment and Bertrand competition yield Cournot outcomes, Bell Journal of Economics 14, 326-337.

Levin, D. (1990), Horizontal mergers: The 50-percent benchmark, American Economic Review 80, 1238-1245.

Lommerud, K.E. and L. Sørgaard (1997), Merger and product range rivalry, International Journal of Industrial Organization 16, 21-42.

Lommerud, K.E., O.R. Straume and L. Sørgard (2005), National versus international merger in unionised oligopoly, Rand Journal of Economics, forthcoming.

Richardson, M. (1999), Trade and competition policies: Concordia discors? Oxford Economic Papers 31, 649-664.

Röller, L.-H, J. Stennek and F. Verboven (2000), Efficiency gains from mergers, Working Paper No. 543, The Research Institute of Industrial Economics, Stockholm.

Salant, S.W., S. Switzer and R.J. Reynolds (1983), Losses from horizontal merger: The effects of an exogenous change in industry structure on Cournot-Nash equilibrium, Quarterly Journal of Economics 98, 185-199.

Schmidt, I. (2001), Wettbewerbspolitik und Kartellrecht, 7. Aufl., Lucius \& Lucius, Stuttgart. 
Sinn, H.-W. (2002), Fusion E.ON-Ruhrgas: Die volkswirtschaftlichen Aspekte. ifo Institut für Wirtschaftsforschung, Forschungsbericht 9.

Williamson, O. (1968), Economies as an antitrust defense: The welfare trade-off, American Economic Review 58, 18-36. 